\title{
Extending Cross Metathesis To Identify Selective HDAC Inhibitors: Synthesis, Biological Activities, and Modeling
}

Samuel Bouchet, ${ }^{\dagger}$ Camille Linot, ${ }^{\ddagger}$ Dusan Ruzic, ${ }^{\S}{ }^{\circledR}$ Danica Agbaba, ${ }^{\S}$ Benoit Fouchaq, ${ }^{\|, \perp}$ Joëlle Roche, ${ }^{\perp, \#}$ Katarina Nikolic, ${ }^{\S}$ Christophe Blanquart, ${ }^{\ddagger, \perp}$ and Philippe Bertrand ${ }^{*},+, \perp \oplus$

${ }^{\dagger}$ Institut de Chimie des Milieux et Matériaux de Poitiers, UMR CNRS 7285, 4 rue Michel Brunet, TSA 51106, B28, 86073 Poitiers cedex 09, France

${ }^{\ddagger}$ CRCINA, INSERM, Université d'Angers, Université de Nantes, Nantes, France

${ }^{\S}$ Department of Pharmaceutical Chemistry, Faculty of Pharmacy, University of Belgrade, Vojvode Stepe 450, 11000 Belgrade, Serbia

"Eurofins-Cerep, Le Bois l'Evêque, 86600 Celle-L'Evescault, France

${ }^{\perp}$ Réseau Epigénétique du Cancéropôle Grand Ouest, France

"\#aboratoire EBI, University of Poitiers, UMR CNRS 7267, F-86073 Poitiers, France

Supporting Information

ABSTRACT: Dissymmetric cross metathesis of alkenes as a convergent and general synthetic strategy allowed for the preparation of a new small series of human histone deacetylases (HDAC) inhibitors. Alkenes bearing Bocprotected hydroxamic acid and benzamide and trityl-protected thiols were used to provide the zinc binding groups and were reacted with alkenes bearing aromatic cap groups. One compound was identified as a selective HDAC6 inhibitor lead. Additional biological evaluation in cancer cell lines demonstrated its ability to stimulate the expression of the epithelial marker E-cadherin and tumor suppressor genes like SEMA3F and p21, suggesting a potential use of this compound for lung cancer treatment. Molecular docking on all 11 HDAC isoforms was used to rationalize the observed biological results.

KEYWORDS: Cross metathesis, histone deacetylases, lung cancer, epigenetics, molecular modeling

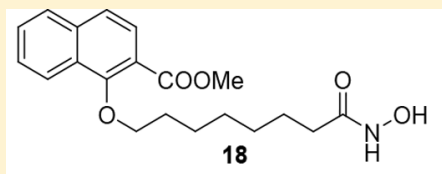

in vitro

HDAC6: $95 \mathrm{nM}$

HDAC1-3,8: 1-3.5 $\mu \mathrm{M}$

HDAC 10: $1.6 \mu \mathrm{M}$

HDAC11: $6.6 \mu \mathrm{M}$

HDAC4-7,9: not active

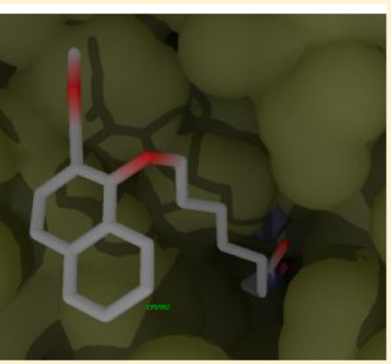

$\mathrm{H}$ uman histone deacetylases (HDAC) and their inhibitors (HDACi) are part of the therapies used to treat human cancers, with four HDACi approved by FDA: SAHA $\mathbf{1}^{1}$ (suberoyl anilide hydroxamic acid, Chart 1, vorinostat) for cutaneous T-cell lymphomas (CTCL), belinostat $2^{2}$ for relapsed or refractory peripheral T-cell lymphoma (PTCL), panobinostat 3 for multiple myeloma, ${ }^{3}$ and FK228 $4^{4}$ (romidepsin) for CTCL. Chidamide $\mathbf{5}$ (Tucidinostat) is approved only in China for PTCL. ${ }^{5}$ Nevertheless, solid tumor treatments with epigenetic compounds are still needed. ${ }^{6}$ HDACs participate in the regulation of gene expression by epigenetic mechanisms affecting chromatin structure and function. ${ }^{7}$ HDACs are a subgroup of 11 zinc-dependent proteins that deacetylate lysine residues of proteins including the core nucleosomal histones $\mathrm{H} 3, \mathrm{H} 4, \mathrm{H} 2 \mathrm{~A}$, and $\mathrm{H} 2 \mathrm{~B}$, leading in turn to the repression of gene expression. Some HDACs deacetylate nonhistone proteins, like HDAC6 for tubulin. HDACs are grouped in three classes, class I (HDAC1-3, 8), class II (IIa HDAC4, 5, 7, 9, and IIb HDAC6, 10), and class IV (HDAC11). The seven NAD-dependent sirtuins (SIRT1-7) represent the class III deacetylases. The overexpression of HDACs in cancer cell lines is correlated with the repressed

expression of tumor suppressor genes (TSG),$^{8-10}$ and HDACi are evaluated alone or in combination. ${ }^{11}$

HDACi are composed of a zinc-binding group (ZBG) linked by a carbon structure to a "cap" group, mostly aromatic, ${ }^{12}$ in interaction with the HDACs external solvent accessible surface. HDACi limitations' are their pharmacokinetics, the side effects at the effective dosing and resistance, ${ }^{13}$ possibly avoided by systemic low dosing administration for a better renormalization of cancer cells. ${ }^{6}$ Bulk substituents and the absence of amide bonds may favor the plasma stability of hydroxamates ${ }^{14}$ in various species. The lack of selectivity of clinically approved HDACi limits their specific applications. ${ }^{15}$ The selectivity against class I HDACs results from para-substituted benzamide inhibitors, ${ }^{16}$ 4-alkylaminomethylbenzhydroxamic acid scaffold, as in tubastatin or nexturastat, gives HDAC6 selectivity, ${ }^{17}$ whereas the trifluoromethyloxadiazole TMP-195 has HDAC7 selectivity.

Received: September 24, 2018

Accepted: May 9, 2019

Published: May 9, 2019 
Chart 1. Some HDAC Inhibitors Illustrate Cap/ZBGs Selectivity Profiles

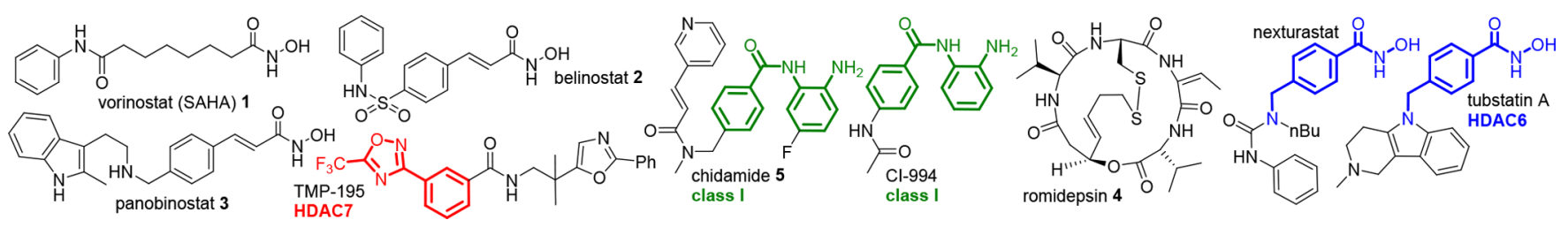

Scheme 1. Preparation of Cap- and ZBG-Bearing Alkenes, Validation, and Use in Cross Metathesis Reaction ${ }^{a}$

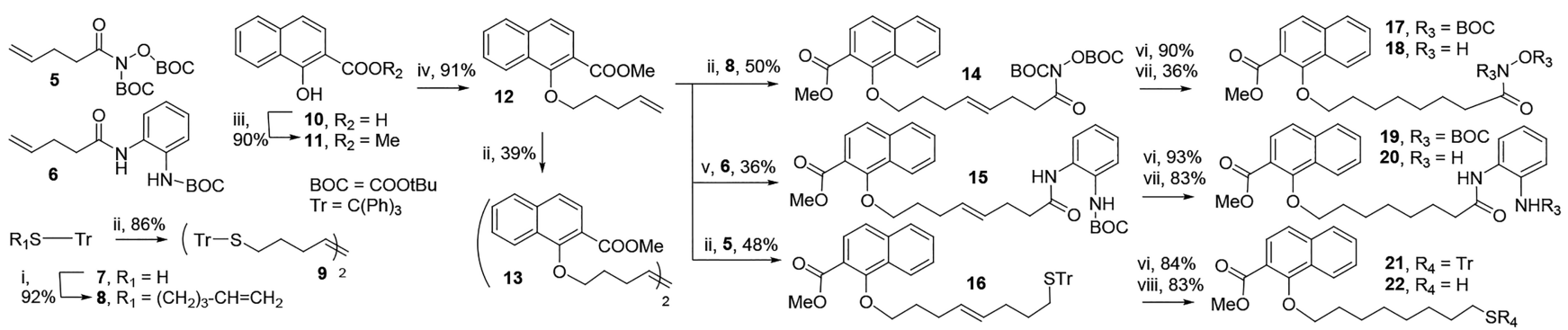

${ }^{a}$ Reagents and conditions: (i) $\mathrm{K}_{2} \mathrm{CO}_{3}, \mathrm{ACN}, \mathrm{Br}-\left(\mathrm{CH}_{2}\right)_{3}-\mathrm{CH}=\mathrm{CH}_{2}$; (ii) Grubbs first generation catalyst, DCM, reflux, $6+1 \mathrm{~h}$; (iii) $\mathrm{CH} \mathrm{H}_{3} \mathrm{OH}$, $\mathrm{H}_{2} \mathrm{SO}_{4}$; (iv) $\mathrm{K}_{2} \mathrm{CO}_{3}$, DMF, $\mathrm{Br}-\left(\mathrm{CH}_{2}\right)_{3}-\mathrm{CH}=\mathrm{CH}_{2}$; (v) second generation catalyst, DCM, reflux; (vi) $\mathrm{H}_{2}, \mathrm{Pd} / \mathrm{C}$, AcOEt; (vii) TFA, DCM; (viii) TFA/TES/DCM 1:0.1:1.

Current compound design is focused on HDAC1-3, 4, 6, and 8 selective inhibitors due to a better biological knowledge. We previously validated cross metathesis (CM) to prepare alkyl-based hydroxamate and benzamide as HDACi. ${ }^{18}$ We present an extension with various ZBGs: hydroxamic acids, thiols, and benzamide as in SAHA, romidepsin, and chidamide. Other ZBG were not explored. ${ }^{19}$ We selected indole and naphthyl ${ }^{20}$ groups found as caps in HDACi. Indoles are known to be reluctant in $\mathrm{CM}$ reaction, but their presence reduces HDACi cardiac toxicity. ${ }^{21}$ A naphtoxy group instead of a naphthylamide may comply with better plasma stability. Despite its simplicity our naphthyl series was unknown but similar to a para-compound used to develop HDAC8 inhibitors with large cap groups. ${ }^{22}$

The alkene 8 was prepared from thiol 7 (Scheme 1) to complement our library ZBG-protected alkenes 5 and $\mathbf{6}$. A general TFA deprotection of the BOC and trityl groups was expected, with TES for the trityl one. The cap-bearing alkene 12 was prepared from naphthol 10. The CM reactivity of alkenes 8 and $\mathbf{1 2}$ was verified and gave compounds 9 and 13, respectively, in moderate to good yields. The CM between the ester 12 and the alkenes 5, 6, and 8 gave access, respectively, to three alkenes 14-16 in good isolated yields with our continuous injection protocol of Grubbs first generation catalyst. The Grubbs second generation catalyst was used for the benzamide 15. The possible dimers formed in each case were separated. Compounds 14-16 were reduced to compounds 17, 19, and 21 , respectively, and deprotection gave the hydroxamate $\mathbf{1 8}$, benzamide $\mathbf{2 0}$, and thiol $\mathbf{2 2}$. The direct $\mathrm{CM}$ with free $\mathrm{NH}$ indole remains difficult (Scheme S1, Supporting Information) and was partly solved by the methylation of the amide $\mathbf{2 3}$ to give $\mathbf{2 4}$, still a poor substrate for CM, even with the Grubbs second generation catalyst, whatever the alkene used. In this series only the reduction of compound 27 to 29 worked, and the deprotection of $29 \mathrm{did}$ not allow recovery of the expected benzamide. The conversion of compound $\mathbf{2 4}$ to a butenylcarboline may be evaluated in the future in CM. These difficulties with the indole series prompted us to focus on the naphthyl series for biological testing. As a summary, Grubbs I catalyst is well suited for thioalkenes and N,O diBoc hydroxamates. The Grubbs II catalyst must be preferred for the benzamide derivatives or other more reactive catalysts. The cap group should be apolar (Supporting Information, Table S1).

Compounds 18, 20, and 22 were tested for global HDAC inhibition using our BRET assays in living cells (Figure S1A$\mathrm{C}, \mathrm{BRET}$ principle, Supporting Information $){ }^{23}$ SAHA $\left(\mathrm{EC}_{50}=\right.$ $1.68 \mu \mathrm{M})$ and CI-994 $\left(\mathrm{EC}_{50}=3.81 \mu \mathrm{M}\right)$ were used as controls (Table 1; Figure S2A, Supporting Information) and gave

Table 1. $\mathrm{EC}_{50}$ for the Induction of Histone Acetylation Measured by BRET Assay in Met-5A Pleural Mesothelial Cells $^{a}$

$\begin{array}{ccccc}\text { Cpd. } & \mathbf{1 8} & \mathbf{2 0} & \text { SAHA } & \text { CI-994 } \\ \mathrm{EC}_{50}(\mu \mathrm{M}) & 7.84 \pm 0.18 & 8.14 \pm 0.32 & 1.68 \pm 0.19 & 3.81 \pm 0.17 \\ { }^{a} \mathrm{EC}_{50} \text { values } & \text { were determined using GraphPad Prism, Prism } 6 \text { for } \\ \text { Windows, by curve fitting using a sigmoidal dose-response model. } \\ \text { Values represent means } \pm \text { standard error of at least three independent } \\ \text { experiments. }\end{array}$

results similar to previous studies. ${ }^{23,24}$ Compounds $\mathbf{1 8}$ and 20 were able to enter cells and to induce an increase of histone $\mathrm{H} 3$ acetylation, illustrated by an increase of the BRET signal. The absence of activity for thiol $\mathbf{2 2}$ may be due to the formation of a disulfide bridge as in psammaplins in the cellular environment. These experiments gave for the hydroxamate 18 an $\mathrm{EC}_{50}$ of $7.84 \mu \mathrm{M}$, and for the benzamides 20 , an $\mathrm{EC}_{50}$ of $8.14 \mu \mathrm{M}$. Comparison of HDACi-induced BRET max values, obtained from dose-response experiments (Figure S2B, Supporting Information), showed that compound 18, SAHA, and CI-994 lead to similar maximal level of histone H3 acetylation, whereas compound $\mathbf{2 0}$ appeared significantly less active. The best HDACi 18 was further studied with SAHA and CI-994 as controls in dose escalation experiments (Figure S3, Supporting Information) for the simultaneous determination of viability (Table 2) and toxicity toward the selected cancer cells. These 
Table 2. $\mathrm{IC}_{50}(\mu \mathrm{M})$ Values for Viability of Meso 163 and 13, A549, and ADCA72 Cell Lines Treated with 18, SAHA, and CI$994(72 \mathrm{~h})^{a}$

\begin{tabular}{lcccr} 
Cpd. & Meso 13 & Meso 163 & \multicolumn{1}{c}{ A549 } & \multicolumn{1}{c}{ ADCA 72 } \\
SAHA & $3.79 \pm 0.18$ & $3.67 \pm 0.17$ & $4.12 \pm 0.18$ & $3.95 \pm 0.23$ \\
CI-994 & $7.83 \pm 0.19$ & $15.77 \pm 0.19$ & $15.96 \pm 0.19$ & $3.90 \pm 0.18$ \\
$\mathbf{1 8}$ & $15.62 \pm 0.12$ & $15.86 \pm 0.14$ & $62.36 \pm 0.18$ & $15.72 \pm 0.16$
\end{tabular}

${ }^{a} \mathrm{IC}_{50}$ values were determined using GraphPad Prism, Prism 6 for Windows, by curve fitting using a sigmoidal dose-response model. Values represent means \pm standard error of at least three independent experiments.

experiments demonstrated that all tested compounds decreased cancer cell viability through induction of toxicity (Figure S3, Supporting Information). The $\mathrm{IC}_{50}$ obtained for the various cancer cell lines used (Table 2) is coherent with the $\mathrm{EC}_{50}$ obtained using BRET assay (Table 1). Compound $\mathbf{1 8}$ is less toxic than SAHA (about 4-fold), and A549 cells are the least sensitive to this compound. We noticed a correlation between induction of histone $\mathrm{H} 3$ acetylation and toxicity. For compound 18, we determined HDAC and sirtuin selectively, using a standardized in vitro assay (Table 3; Figure S4,

Table 3. Inhibition Profile and Isoform Selectivity of Compound 18 Compared to Reference Compounds ${ }^{a}$

\begin{tabular}{ccrrr} 
& & & \multicolumn{2}{c}{$\mathrm{IC}_{50}(\mu \mathrm{M})$} \\
\cline { 4 - 6 } target & \% inhibition 18, 10 $\mu \mathrm{M}$ & ref & $\mathbf{1 8}$ & ref \\
HDAC1 & 84,7 & TSA & 3.5 & 0.011 \\
HDAC2 & 67,1 & TSA & 3.4 & 0.016 \\
HDAC3 & 87,9 & TSA & 1.0 & 0.010 \\
HDAC4 & $-4,8$ & TSA & na & 2.5 \\
HDAC5 & 2,8 & TSA & na & 1.6 \\
HDAC6 & 104,1 & TSA & 0.095 & 0.022 \\
HDAC7 & $-16,3$ & TSA & na & 0.98 \\
HDAC8 & 93,1 & TSA & 1.6 & 0.79 \\
HDAC9 & $-14,3$ & TSA & na & 5.1 \\
HDAC10 & 82,3 & TSA & 1.6 & 0.040 \\
HDAC11 & 57,2 & b & 6.6 & 5.2 \\
sirtuin1 & $-2,6$ & c & Nd & 6.7 \\
sirtuin2 & $-11,8$ & c & Nd & 17 \\
sirtuin3 & $-8,2$ & d & Nd & 36 \\
sirtuin6 & $-13,4$ & EX527 & &
\end{tabular}

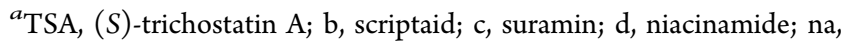
not active; $\mathrm{Nd}$, not determined; ref, reference compound.

Supporting Information). At $10 \mu \mathrm{M}$ concentration, compound 18 was able to partially inhibit HDAC classes I (HDAC1,2,3,8), IIb (HDAC6,10), and IV (HDAC11), and no inhibition was noticed for class IIa and class III. One hundred percent inhibition was obtained only for HDAC6 (class IIb). The dose-responses in vitro (Figure S4, Supporting Information) showed that compound $\mathbf{1 8}$ is selective for HDAC6 $\left(\mathrm{IC}_{50}=95 \mathrm{nM}\right.$, Table 3$)$, about 10 fold less active for HDAC3, and 17- to 37-fold less for the other isoforms. The reference compound TSA was not selective, with better activity against HDAC HDAC1-3,6 and 10 than for other isoforms. The selective inhibition of HDAC6 prompted us to examine histone $\mathrm{H} 3$ and $\alpha$-tubulin acetylation in malignant pleural mesothelioma (MPM, meso 163) and lung adenocarcinoma (ADCA, A549) cells by western-blot. SAHA was used as a control for the induction of histone $\mathrm{H} 3$, and $\alpha$-tubulin acetylation and CI-994 for the only induction of histone $\mathrm{H} 3$ acetylation. In meso 163 cells (Figure 1A upper panels), SAHA and compound $\mathbf{1 8}$ induced a rapid and transitory histone $\mathrm{H} 3$ acetylation, whereas the benzamide CI-994 induced rapid and sustained histone $\mathrm{H} 3$ acetylation. The changes in histone $\mathrm{H} 3$ acetylation modulate the expression of a wide range of genes. In this study, we measured the mRNA level of E-cadherin, an "epitheloid status" marker of epithelial to mesenchymal transition (EMT), ${ }^{25}$ and the expression of two TSG was evaluated: Semaphorin-3F (Sema-3F), which reduces tumor angiogenesis and progression and is lost or reduced in lung cancers, ${ }^{26}$ and $\mathrm{p} 21$, which is involved in cell cycle. ${ }^{27}$

Figure 1B shows that compound 18, SAHA, and CI-994 induced the expression of E-cadherin and of both TSGs suggesting a beneficial effect on MPM and lung cancer cells. Like SAHA, compound $\mathbf{1 8}$ induced a sustained $\alpha$-tubulin acetylation demonstrating its inhibitory effect on cytoplasmic HDAC6, coherent with its high HDAC6 inhibition activity. ${ }^{28}$ As expected, CI-994 did not increase $\alpha$-tubulin acetylation according to the specific activity of benzamide on nuclear HDAC. $^{29}$ In A549 cells (Figure 1A lower panels), similar results were obtained. The only difference with meso 163 cells was the sustained activity of SAHA and compound 18 on histone $\mathrm{H} 3$ acetylation over time.

Insight into the ligand positioning and binding modes of compound 18 into 11 metal-dependent HDAC isoforms was performed by molecular docking study. Docking simulations were able to reproduce the cocrystal inhibitor binding modes with RMSD values below $1.5 \AA$ for each isoform and took into account the important interactions between hydroxamic acid derivatives in the active center of HDAC isoforms. ${ }^{30,31}$ The method was additionally validated by comparing the ChemScore Fitness Function (CSFF) calculated for (S)-TSA and compound 18 with their experimentally obtained $\mathrm{IC}_{50}$ values within each isoform. ${ }^{32}$

GOLD CSFF values calculated for ligand-specific HDAC were in good agreement with the experimental inhibitory profiles of $(S)$-TSA and compound 18 compared within the same isoform (Figures S5-S8 and Table S2, Supporting Information). Compound 18 chelates with the $\mathrm{Zn}^{2+}$ ion inside the HDAC binding pockets, except for the isoforms that belong to the HDAC class IIa (HDAC5/HDAC7 and HDAC9). The binding modes of compound 18 into active pockets of HDAC1 and both catalytic domains of HDAC6 (CDI and CDII) are presented in Figure 2 (other HDACs in Figures S9-S20 and Table S2, Supporting Information). HDAC6 CDII has a wider hydrophobic rim of the catalytic site (14.015 $\AA$ ) comparing to the hydrophobic rim of HDAC1 (9.765 $\AA)$. Furthermore, the second argument for more favorable interaction of compound $\mathbf{1 8}$ with HDAC6 is a deeper active channel, which is less restricted for inhibitor access. ${ }^{32}$ The naphthalene moiety of compound 18 forms favorable $\pi-\pi$ interaction with aromatic residue of Phe680 in HDAC6 CDII. In addition, $\pi$-sulfur interactions are formed between Met682 and naphthalene ring (Figure S14, Supporting Information). A 


\section{A}

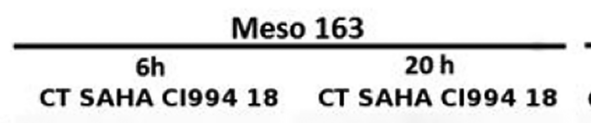

\begin{tabular}{cc}
\multicolumn{3}{c}{ A 549} \\
\hline 6h & $20 \mathrm{~h}$ \\
CT SAHA CI994 18 & CT SAHA CI994 18
\end{tabular}
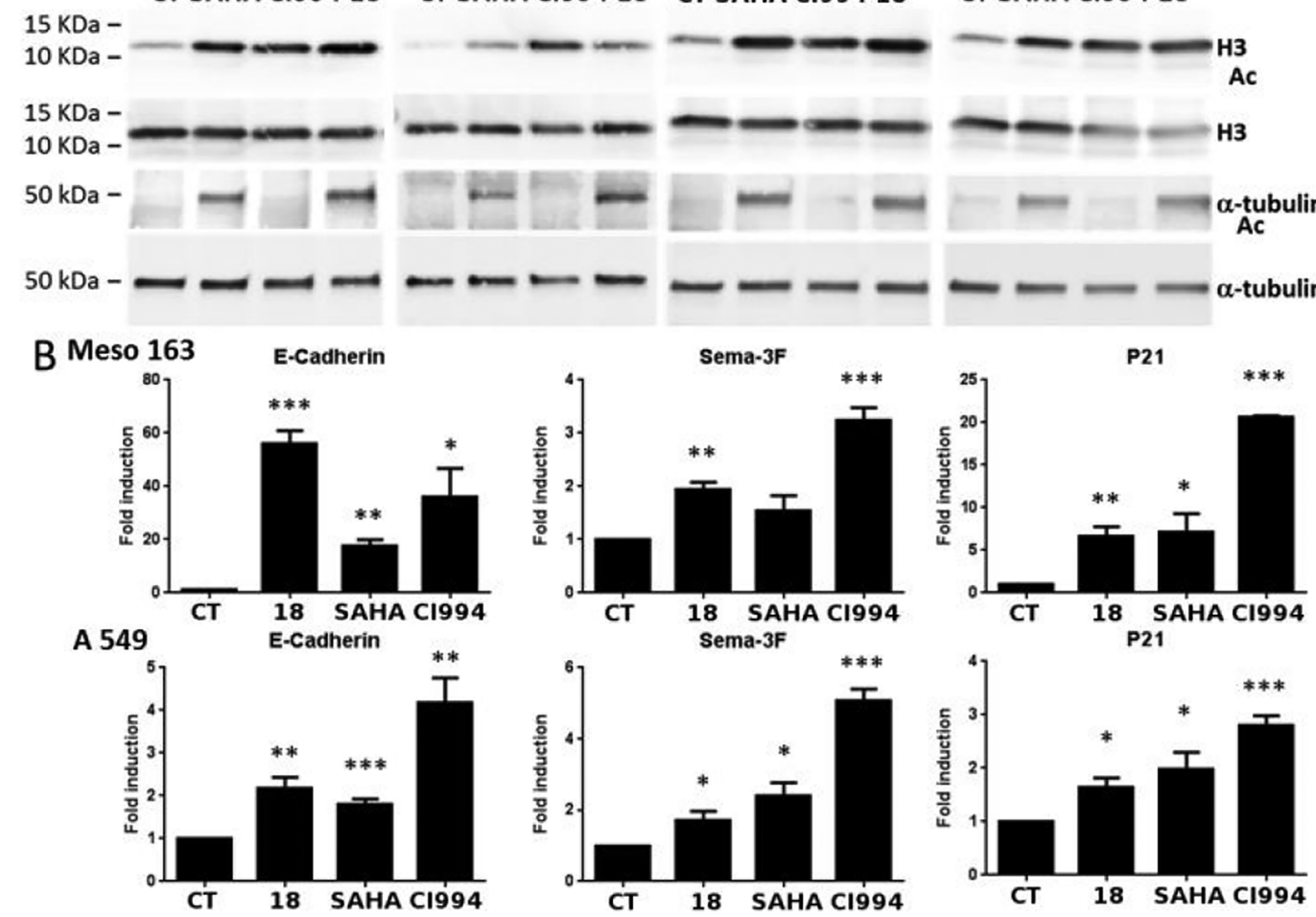

Figure 1. Effect of compound $18(20 \mu \mathrm{M})$, SAHA $(2.5 \mu \mathrm{M})$, and CI-994 $(10 \mu \mathrm{M})$ on (A) histone H3 and $\alpha$-tubulin acetylation in MPM and lung ADCA cells. Meso 163 and A549 cells were treated with the compounds for 6 or 20 h. Histone H3 and $\alpha$-tubulin acetylation were analyzed using western-blot. Left column indicates the molecular weight; and on (B) E-cadherin, Sema-3F, and P21 expression in MPM and lung ADCA cells. Meso 163 and A549 cells were treated with the compounds for $24 \mathrm{~h}$. mRNA expression of E-cadherin, Sema-3F, and p21 was measured using realtime PCR. Results are means \pm SEM of four independent experiments. ${ }^{*} p<0.05 ; * *<0.01 ; * * p<0.001$.
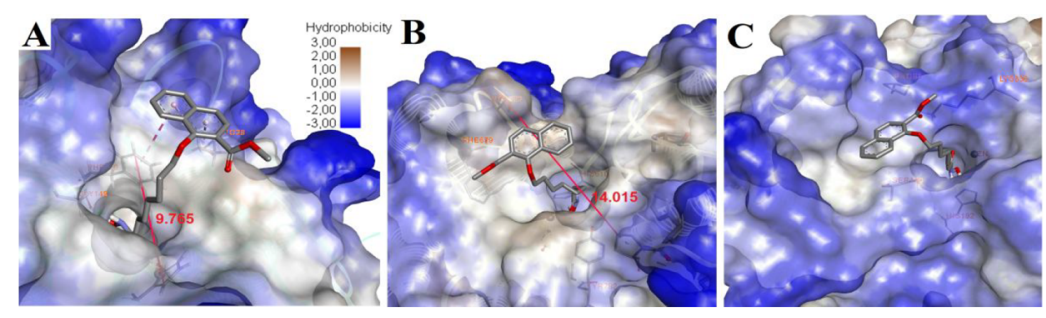

Figure 2. Comparative presentation of hydrophobic rim of the catalytic sites in HDAC1 homology model (A), crystal structure of human HDAC6 second catalytic domain (B), and first catalytic domain (C) with compound 18.

bidentate binding mode was inspected for compound 18 inside the binding pocket of HDAC6, whereas the monodentate coordination was observed for the same compound in the active site of HDAC1. The high HDAC6 inhibitory potency of this compound could be explained by favorable interactions of the naphthalene CAP group with the side chains located in the outer rim of HDAC6 enzyme, as well as bidentate coordination with $\mathrm{Zn}^{2+}$ ion. Additionally, the higher HDAC6 potency of compound 18 may be also explained by the differences in the length of the active pockets. It is previously shown that the compounds with six carbon-spacer possess optimal distance between hydroxamic acid and CAP group for HDAC1 inhibitory activity. ${ }^{33}$ When the spacer of the HDAC1 inhibitor is longer than six carbons, it is less favorable to make the hydrophobic interactions to the solvent exposed entrance of the catalytic site. Compound $\mathbf{1 8}$ has an aliphatic linker constructed of eight carbon atoms, which may explain its selective HDAC6 inhibitory profile and less pronounced interactions with the side chains in the outer rim of class I HDACs. Domain-selective HDAC6 inhibitors studies ${ }^{30}$ prompted us to examine possible domain selective affinity for compound 18. We observed slightly different CSFF values calculated for $(S)$-TSA and compound $\mathbf{1 8}$ between HDAC6 catalytic domains (higher CSFF for CDI). To define whether the compound 18 possesses higher affinity for CDI of HDAC6 isoform, advanced structure based in silico and crystallographic studies should be performed, for the more precise determination of the ligand's domain selectivity.

In conclusion, CM was successfully used to prepare rapidly with a generic method a series of alkyl-based HDAC inhibitors bearing the most common ZBGs, and one of them is an in vitro nanomolar selective HDAC6 inhibitor. The method can be adapted to inhibitors of other relevant biological targets. The methodology should be applicable in combinatorial strategies. 
Molecular docking rationalized the inhibition profile of compound 18, introducing for the first time analysis of both CD1 and CD2 domains of HDAC6. The biological interest of compound 18 was demonstrated, with an increased acetylation of histones and $\alpha$-tubulin, associated with the stimulation of the expression of E-cadherin and TSGs such as SEMA3F and $\mathrm{p} 21$.

\section{EXPERIMENTAL PROCEDURES}

All biologically tested compounds were $95 \%+$ pure as determined by HPLC. Typical synthetic sequence illustrated for compound 18. DCM, dichloromethane; TFA, trifluoroacetic acid; TES, triethylsilane; EA, ethyl acetate; PE, petroleum ether; TEA, trimethylamine; $\mathrm{ACN}$, acetonitrile.

Methyl (Z/E)-1-((8-((tert-butoxycarbonyl) ((tert-butoxycarbonyl)oxy)amino)-8-oxooct-4-en-1-yl)oxy)-2-naphthoate 14. Grubbs catalyst $(50 \mathrm{mg})$ in DCM $(3 \mathrm{~mL})$ was added over $6 \mathrm{~h}(0,5 \mathrm{~mL} / \mathrm{h}$ rate $)$ to a boiling solution of $5(89 \mathrm{mg}, 0.33 \mathrm{mmol})$ and $\mathbf{1 2}(208 \mathrm{mg}, 0.66$ $\mathrm{mmol})$ in DCM $(3 \mathrm{~mL})$ and refluxed $1 \mathrm{~h}$ more. After cooling, the solvent was removed (vacuum) and purification (flash chromatography silica, PE/EA/TEA 99.5/0/0.5, $250 \mathrm{~mL}, 97 / 2.5 / 0.5,1 \mathrm{~L}, 94.5 /$ 5/0.5, $1 \mathrm{~L}$ followed by preparative thin layer chromatography; PE/EA 97.5/2.5 and 95/5) gave $14(88 \mathrm{mg}, 48 \%)$ as an orange oil. ${ }^{1} \mathrm{H}$ NMR $\left(\mathrm{CDCl}_{3}\right) \delta$ ppm: $1.53(4 \mathrm{~s}, 18 \mathrm{H}), 2.02(\mathrm{~m}, 2 \mathrm{H}), 2.34(\mathrm{~m}, 4 \mathrm{H}), 2.92$ $(\mathrm{m}, 2 \mathrm{H}), 3.95(3 \mathrm{~s}, 3 \mathrm{H}), 4.12(\mathrm{dt}, 2 \mathrm{H}, J=1.0,6.6 \mathrm{~Hz}), 5.55(\mathrm{~m}, 2 \mathrm{H})$, $7.58(\mathrm{~m}, 3 \mathrm{H}), 7.84(\mathrm{~m}, 2 \mathrm{H}), 8.27(\mathrm{dd}, 1 \mathrm{H}, J=6.49,7.33 \mathrm{~Hz}) .{ }^{13} \mathrm{C}$ NMR $\left(\mathrm{CDCl}_{3}\right) \delta$ ppm: 23.9, 27.4, 27.5, 27.9, 28.0, 29.05, 29.1, 30.1, $30.3,30.4,36.8,52.2,85.2,86.0,119.2,123.4,123.7,126.4,126.7$, $127.8,128.3,128.8,129.7,130.2,130.8,136.7,157.4,166.9,170.2$. HRMS Calcd. for $\mathrm{C}_{30} \mathrm{H}_{39} \mathrm{NNaO}_{9}[\mathrm{M}+\mathrm{Na}]^{+}: 580,2517$, found 580.2524 .

Methyl 1-((8-(hydroxyamino)-8-oxooctyl)oxy)-2-naphthoate 18. TFA $(0.33 \mathrm{~mL}, 4 \mathrm{mmol})$ was added to a solution of $17(84 \mathrm{mg}$, $0.15 \mathrm{mmol}$ ) in DCM, and the solution was stirred for $3 \mathrm{~h}$. The crude mixture was diluted with $\mathrm{EA}$ and washed (saturated aqueous $\mathrm{NaCl} 3$ $\times 5 \mathrm{~mL}$ ). The combined aqueous extracts were neutralized (saturated aqueous $\mathrm{NaHCO}_{3}, \mathrm{pH} 7$ ) and extracted (EA, $3 \times 20 \mathrm{~mL}$ ). The combined organic layers were dried $\left(\mathrm{MgSO}_{4}\right)$ and concentrated under vacuum to yield $18(20 \mathrm{mg}, 36 \%)$ as an orange oil. ${ }^{1} \mathrm{H}$ NMR $\left(\mathrm{CDCl}_{3}\right)$ $\delta$ ppm: $1.33(\mathrm{~m}, 4 \mathrm{H}), 1.52(\mathrm{~m}, 4 \mathrm{H}), 1.85(\mathrm{t}, 2 \mathrm{H}, J=7.4 \mathrm{~Hz}), 1.96(\mathrm{t}$, $2 \mathrm{H}, J=7.3 \mathrm{~Hz}), 3.89(\mathrm{~s}, 3 \mathrm{H}), 4.05(\mathrm{t}, 2 \mathrm{H}, J=6.5 \mathrm{~Hz}), 7.66(\mathrm{~m}, 2 \mathrm{H})$, $7.75(\mathrm{~s}, 2 \mathrm{H}), 7.99(\mathrm{dd}, 1 \mathrm{H}, J=6.1,7.1 \mathrm{~Hz}), 8.19(\mathrm{dd}, 1 \mathrm{H}, J=6.3,7,2$ $\mathrm{Hz}), 8.69(\mathrm{~s}, 1 \mathrm{H}), 10.37(\mathrm{~s}, 1 \mathrm{H}) .{ }^{13} \mathrm{C}$ NMR $\left(\mathrm{CDCl}_{3}\right) \delta \mathrm{ppm:} \mathrm{25.6,}$ 25.9, 29.0, 29.1, 30.2, 32.7, 52.7, 76.4, 119.8, 123.5, 123.9, 126.7, 127.4, 128.5, 128.5, 129.0, 136.5, 156.6, 166.8, 169.6. HRMS Calcd. for $\mathrm{C}_{20} \mathrm{H}_{25} \mathrm{NNaO}_{5}[\mathrm{M}+\mathrm{Na}]^{+}:$382.1625, found 382.1626.

\section{ASSOCIATED CONTENT}

\section{S Supporting Information}

The Supporting Information is available free of charge on the ACS Publications website at DOI: 10.1021/acsmedchemlett. 8 b00440.

Synthesis, characterizations for all compounds, ${ }^{1} \mathrm{H} /{ }^{13} \mathrm{C}$ NMR spectra and HPLC data for compounds 18, 20, and 22, biological experiments, docking methods, and Figures S1-S20 (PDF)

PDB files (ZIP)

\section{AUTHOR INFORMATION}

\section{Corresponding Author}

*E-mail: Philippe.bertrand@univ-poitiers.fr.

ORCID 0

Dusan Ruzic: 0000-0002-0546-8265

Philippe Bertrand: 0000-0001-8171-2031

\section{Author Contributions}

The manuscript was written through contributions of all authors.

\section{Funding}

Regions Nouvelle Aquitaine and Pays de la Loire, Ligue Contre le Cancer: committees of Vendée and CharenteMaritime. D.A., K.N., and D.R. acknowledge the project (contract no. 172033) supported by the Ministry of Education, Science, and Technological Development of the Republic of Serbia.

\section{Notes}

The authors declare no competing financial interest.

\section{ACKNOWLEDGMENTS}

Authors thank the Centre National de la Recherche Scientifique, University of Poitiers, COST Action CM1406, Professor Olaf Wiest group for providing us homology models of 11 HDAC isoforms (HDAC1-HDAC11) used for molecular docking study.

\section{REFERENCES}

(1) Duvic, M.; Vu, J. Vorinostat: A New Oral Histone Deacetylase Inhibitor Approved for Cutaneous T-Cell Lymphoma. Expert Opin. Investig. Drugs 2007, 16, 1111-1120.

(2) Poole, R. Belinostat: First Global Approval. Drugs 2014, 74, $1543-1554$

(3) Fenichel, M. P. FDA Approves New Agent for Multiple Myeloma. J. Natl. Cancer Inst. 2015, 107, djv165.

(4) Grant, C.; Rahman, F.; Piekarz, R.; Peer, C.; Frye, R.; Robey, R. W.; Gardner, E. R.; Figg, W. D.; Bates, S. E. Romidepsin: A New Therapy for Cutaneous T-Cell Lymphoma and a Potential Therapy for Solid Tumors. Expert Rev. Anticancer Ther. 2010, 10, 997-1008.

(5) Shi, Y.; Jia, B.; Xu, W.; Li, W.; Liu, T.; Liu, P.; Zhao, W.; Zhang, H.; Sun, X.; Yang, H.; Zhang, X.; Jin, J.; Jin, Z.; Li, Z.; Qiu, L.; Dong, M.; Huang, X.; Luo, Y.; Wang, X.; Wang, X.; Wu, J.; Xu, J.; Yi, P.; Zhou, J.; He, H.; Liu, L.; Shen, J.; Tang, X.; Wang, J.; Yang, J.; Zeng, Q.; Zhang, Z.; Cai, Z.; Chen, X.; Ding, K.; Hou, M.; Huang, H.; Li, X.; Liang, R.; Liu, Q.; Song, Y.; Su, H.; Gao, Y.; Liu, L.; Luo, J.; Su, L.; Sun, Z.; Tan, H.; Wang, H.; Wang, J.; Wang, S.; Zhang, H.; Zhang, X.; Zhou, D.; Bai, O.; Wu, G.; Zhang, L.; Zhang, Y. Chidamide in Relapsed or Refractory Peripheral T Cell Lymphoma: A Multicenter Real-World Study in China. J. Hematol. Oncol.J. Hematol Oncol 2017, $10,69$.

(6) Azad, N.; Zahnow, C. A.; Rudin, C. M.; Baylin, S. B. The Future of Epigenetic Therapy in Solid Tumours: Lessons from the Past. Nat. Rev. Clin. Oncol. 2013, 10, 256-266.

(7) Arrowsmith, C. H.; Bountra, C.; Fish, P. V.; Lee, K.; Schapira, M. Epigenetic Protein Families: A New Frontier for Drug Discovery. Nat. Rev. Drug Discovery 2012, 11, 384-400.

(8) Feng, D.; Wu, J.; Tian, Y.; Zhou, H.; Zhou, Y.; Hu, W.; Zhao, W.; Wei, H.; Ling, B.; Ma, C. Targeting of Histone Deacetylases to Reactivate Tumour Suppressor Genes and Its Therapeutic Potential in a Human Cervical Cancer Xenograft Model. PLoS One 2013, 8, No. e80657.

(9) Wagner, T.; Brand, P.; Heinzel, T.; Krämer, O. H. Histone Deacetylase 2 Controls P53 and Is a Critical Factor in Tumorigenesis. Biochim. Biophys. Acta, Rev. Cancer 2014, 1846, 524-538.

(10) Ma, Y.; Jin, H.; Wang, X.; Shin, V. Y.; Chen, D.; Chen, Y.; Feng, L.; Xu, W.; Lin, X.; Chu, J.; Sun, J.; Pan, M.; Yue, Y. Histone Deacetylase 3 Inhibits New Tumor Suppressor Gene DTWD1 in Gastric Cancer. Am. J. Cancer Res. 2015, 5, 663-673.

(11) Mottamal, M.; Zheng, S.; Huang, L. T.; Wang, G. Histone Deacetylase Inhibitors in Clinical Studies as Templates for New Anticancer Agents. Molecules 2015, 20, 3898.

(12) Roche, J.; Bertrand, P. Inside HDACs with More Selective HDAC Inhibitors. Eur. J. Med. Chem. 2016, 121, 451-483. 
(13) Robey, R. W.; Chakraborty, A. R.; Basseville, A.; Luchenko, V.; Bahr, J.; Zhan, Z.; Bates, S. E. Histone Deacetylase Inhibitors: Emerging Mechanisms of Resistance. Mol. Pharmaceutics 2011, 8, 2021-2031.

(14) Hermant, P.; Bosc, D.; Piveteau, C.; Gealageas, R.; Lam, B.; Ronco, C.; Roignant, M.; Tolojanahary, H.; Jean, L.; Renard, P.-Y.; Lemdani, M.; Bourotte, M.; Herledan, A.; Bedart, C.; Biela, A.; Leroux, F.; Deprez, B.; Deprez-Poulain, R. Controlling Plasma Stability of Hydroxamic Acids: A MedChem Toolbox. J. Med. Chem. 2017, 60, 9067-9089.

(15) Witt, O.; Deubzer, H. E.; Milde, T.; Oehme, I. HDAC Family: What Are the Cancer Relevant Targets? Cancer Lett. 2009, 277, 8-21.

(16) Bressi, J. C.; Jennings, A. J.; Skene, R.; Wu, Y.; Melkus, R.; Jong, R. D.; O'Connell, S.; Grimshaw, C. E.; Navre, M.; Gangloff, A. R. Exploration of the HDAC2 Foot Pocket: Synthesis and $\{\mathrm{SAR}\}$ of Substituted N-(2-Aminophenyl)Benzamides. Bioorg. Med. Chem. Lett. 2010, 20, 3142-3145.

(17) Estiu, G.; Greenberg, E.; Harrison, C. B.; Kwiatkowski, N. P.; Mazitschek, R.; Bradner, J. E.; Wiest, O. Structural Origin of Selectivity in Class II-Selective Histone Deacetylase Inhibitors. J. Med. Chem. 2008, 51, 2898-2906.

(18) Zwick, V.; Nurisso, A.; Simões-Pires, C.; Bouchet, S.; Martinet, N.; Lehotzky, A.; Ovadi, J.; Cuendet, M.; Blanquart, C.; Bertrand, P. Cross Metathesis with Hydroxamate and Benzamide BOC-Protected Alkenes to Access \{HDAC\} Inhibitors and Their Biological Evaluation Highlighted Intrinsic Activity of BOC-Protected Dihydroxamates. Bioorg. Med. Chem. Lett. 2016, 26, 154-159.

(19) Bertrand, P. Inside HDAC with HDAC Inhibitors. Eur. J. Med. Chem. 2010, 45, 2095-2116.

(20) Valente, S.; Trisciuoglio, D.; De Luca, T.; Nebbioso, A.; Labella, D.; Lenoci, A.; Bigogno, C.; Dondio, G.; Miceli, M.; Brosch, G.; Del Bufalo, D.; Altucci, L.; Mai, A. 1,3,4-Oxadiazole-Containing Histone Deacetylase Inhibitors: Anticancer Activities in Cancer Cells. J. Med. Chem. 2014, 57, 6259-6265.

(21) Shultz, M. D.; Cao, X.; Chen, C. H.; Cho, Y. S.; Davis, N. R.; Eckman, J.; Fan, J.; Fekete, A.; Firestone, B.; Flynn, J.; Green, J.; Growney, J. D.; Holmqvist, M.; Hsu, M.; Jansson, D.; Jiang, L.; Kwon, P.; Liu, G.; Lombardo, F.; Lu, Q.; Majumdar, D.; Meta, C.; Perez, L.; Pu, M.; Ramsey, T.; Remiszewski, S.; Skolnik, S.; Traebert, M.; Urban, L.; Uttamsingh, V.; Wang, P.; Whitebread, S.; Whitehead, L.; YanNeale, Y.; Yao, Y.-M.; Zhou, L.; Atadja, P. Optimization of the in Vitro Cardiac Safety of Hydroxamate-Based Histone Deacetylase Inhibitors. J. Med. Chem. 2011, 54, 4752-4772.

(22) Tang, W.; Luo, T.; Greenberg, E. F.; Bradner, J. E.; Schreiber, S. L. Discovery of Histone Deacetylase 8 Selective Inhibitors. Bioorg. Med. Chem. Lett. 2011, 21, 2601-2605.

(23) Blanquart, C.; François, M.; Charrier, C.; Bertrand, P.; Grégoire, M. Pharmacological Characterization of Histone Deacetylase Inhibitor and Tumor Cell-Growth Inhibition Properties of New Benzofuranone Compounds. Curr. Cancer Drug Targets 2011, 11, 919-928.

(24) Delatouche, R.; Denis, I.; Grinda, M.; El Bahhaj, F.; Baucher, E.; Collette, F.; Heroguez, V.; Gregoire, M.; Blanquart, C.; Bertrand, P. Design of PH Responsive Clickable Prodrugs Applied to Histone Deacetylase Inhibitors: A New Strategy for Anticancer Therapy. Eur. J. Pharm. Biopharm 2013, 85, 862-72.

(25) Ohira, T.; Gemmill, R. M.; Ferguson, K.; Kusy, S.; Roche, J.; Brambilla, E.; Zeng, C.; Baron, A.; Bemis, L.; Erickson, P.; Wilder, E.; Rustgi, A.; Kitajewski, J.; Gabrielson, E.; Bremnes, R.; Franklin, W.; Drabkin, H. A. WNT7a Induces E-Cadherin in Lung Cancer Cells. Proc. Natl. Acad. Sci. U. S. A. 2003, 100, 10429-10434.

(26) Potiron, V. A.; Roche, J.; Drabkin, H. A. Semaphorins and Their Receptors in Lung Cancer. Cancer Lett. 2009, 273, 1-14.

(27) Abbas, T.; Dutta, A. P21 in Cancer: Intricate Networks and Multiple Activities. Nat. Rev. Cancer 2009, 9, 400-414.

(28) Hubbert, C.; Guardiola, A.; Shao, R.; Kawaguchi, Y.; Ito, A.; Nixon, A.; Yoshida, M.; Wang, X.-F.; Yao, T.-P. HDAC6 Is a Microtubule-Associated Deacetylase. Nature 2002, 417, 455-458.
(29) Bracker, T. U.; Sommer, A.; Fichtner, I.; Faus, H.; Haendler, B.; Hess-Stumpp, H. Efficacy of MS-275, a Selective Inhibitor of Class I Histone Deacetylases, in Human Colon Cancer Models. Int. J. Oncol. 2009, 35, 909-920.

(30) Hai, Y.; Christianson, D. W. Histone Deacetylase 6 Structure and Molecular Basis of Catalysis and Inhibition. Nat. Chem. Biol. 2016, 12, 741-747.

(31) Zhou, J.; Li, M.; Chen, N.; Wang, S.; Luo, H.-B.; Zhang, Y.; $\mathrm{Wu}, \mathrm{R}$. Computational Design of a Time-Dependent Histone Deacetylase 2 Selective Inhibitor. ACS Chem. Biol. 2015, 10, 687692.

(32) Miyake, Y.; Keusch, J. J.; Wang, L.; Saito, M.; Hess, D.; Wang, X.; Melancon, B. J.; Helquist, P.; Gut, H.; Matthias, P. Structural Insights into HDAC6 Tubulin Deacetylation and Its Selective Inhibition. Nat. Chem. Biol. 2016, 12, 748-754.

(33) Schäfer, S.; Saunders, L.; Eliseeva, E.; Velena, A.; Jung, M.; Schwienhorst, A.; Strasser, A.; Dickmanns, A.; Ficner, R.; Schlimme, S.; Sippl, W.; Verdin, E.; Jung, M. Phenylalanine-Containing Hydroxamic Acids as Selective Inhibitors of Class IIb Histone Deacetylases (HDACs). Bioorg. Med. Chem. 2008, 16, 2011-2033. 